\title{
VISUAL AESTHETIC EXPRESSION ON USER-GENERATED CONTENT BY THE NET GENERATION (EXISTENCE, ROLES, AND OPPORTUNITIES IN CYBERSPACE)
}

\author{
Hasanah Md. AMIN \\ Mara University of Technology, Malaysia \\ hasanah_mdamin@yahoo.com
}

\begin{abstract}
The overload content on Internet, has a direct connection with cyberspace particularly UGC. The space, the content, the creator, and the user are the complete component of cyberspace. The existence of cyberspace and its growing contents is real and overwhelming, where the creator roles is becoming demanding, and user opportunities are growing high. Visual as one of the properties of cyber contents is increasingly becoming more significant and popular amongst creator and user. Visual with aesthetic power could impress, influence, and favor biasness amongst the user. The content creator who knows how to manipulate this visuals and aesthetic expression can dominate the scenario and user who is 'expressive literate' will gain much from the scenes. User who understands visual aesthetic will be rewarded with competence, confidence, and certainly, a personality enhanced experience in carrying task when participating in this chaotic but promising cyber world. This article with the support of public-opinion polls and discussion forums explains the complete component of cyberspace, revealing some possible cognitive meanings, and emotional values behind it existence, it roles, and the opportunities offered by visual aesthetic. This is a space of opportunities where the ideal is - not 'what you want', but 'how you want it to benefits you'.
\end{abstract}

Keywords: Aesthetic expression, Net generation, User-generated content.

\section{INTRODUCTION}

This is a part of the visual aesthetic study on user-generated content (UGC). The aim of this article is to gain knowledge from related literature and research regarding UGC, which focus on aesthetic expression by the Net generation. This is to establish my understanding, stimulates and generates my own view on aesthetic and UGC.

The cyberspace grows and gains popularity and it seems will rule the future world. Visual as one of the properties of cyber contents is increasingly becoming more significant and popular amongst creator and user. I am seeking the knowledge on why this scenario happens, what is the consequences, and what are the advantages behind the situation. Through text reading, works, and research by scholars, I hope to uncover the fact of the scenario for my further research. Concurrently, to have a clearer picture on users understanding, their opinions and knowledge regarding aesthetic and UGC, polls and forums was conducted on a blog http://www.ccomme.wordpress.com and several online forums; Ustazah Bahyiah Facebook, Carigold http://carigold.com/; Melayu.com http://www.melayu.com/v2/sembang2/, Mesra.net http://www.mesra.net/forum, and Putera.com http://forum.putera.com/ which take place during October, November, and December 2010. This is also to view the contiguous issues on aesthetics and the UGC. Eventually suggest a possible means of tackling the related issues.

Every existence in this world has purposes and functions. The cyberspace with the complete component of the space, the content, the creator, and the user has several distinctive functions. Without any one of these components, which compliment to one another, the cyberspace will not grows tremendously. The Internet pioneer Vinton Gray three golden rules - 'nobody 
owns it, everybody use it and anybody can add services to it', quoted from Tapscott and William $(2008)^{[1]}$ say a lots, from using to stealing, from naïve to expert user, and from quality to crud contents. To some, this space is a symbol of knowledge, achievement, advancement, and to others is, young generation, vibrant, freedom, and expression ... opportunities to both, in any sense... The cyberspace is a living without system, a lawless land, and a ground for opportunist operations. That is the reality of the cyberspace. The space, the content, the creator, and the user are the complete components of an evolving cyberspace that will alive and never stop, and in fact, it will rules the future real world.

\subsection{THE EXISTENCE OF CYBERSPACE}

We could not prevent the inevitable of technology advancement and people involvement in shaping cyberspace and the success of UGC. Technologies play an important role: the hardware provide the platform and allows the creator to store massive contents; the software, particularly Web 2.0, empowering the creator to develop creative contents; and the broadband connection enable the creator to transfer quickly and reliably large amount of contents to user. User has all the tools provided by the technology for participating in UGC. The development of software allowed user to actively take part in the participatory culture which nurture this concept; peer-to-peer, collaborates, meshing, mixing, and co-creation. Many research statistics have shown that the Net generation is the biggest creator and user of UGC. The eight Net generation norms is a cluster of attitudes and behaviors that define the generation (Tapscott, 2009) $^{[2]}$ have direct connection with the Internet and certainly give the characteristic to UGC.

The existence of UGC will retain and participatory trend will continue with good momentum. This is because the UGC cover up every essential aspects of technical, (efficient, simple, and convenience), psychology (spontaneously and without coercion, openness and willingness, expression and creativity, freedom, and rewards), social (celebrity, fame, notoriety or prestige), and economic (instant and cheap) respectively.

\subsection{THE EXISTENCE AND THE GROWING CONTENTS}

The real scenario is contents overload. There are several statistics on web users and content creators that shows different figures. International Telecommunication Union estimates two billion people online by the end of 2010. However, statistic is growing. Janna Anderson and Lee Rainie in the Future of the Internet 2010 Survey Results, Pew Reports ${ }^{[3]}$, said by 2020 , there would be unprecedented access to more information, and people will work in Internetbased applications, instead of in applications that run on a PC OS. Peter Norvig, as cited in the Future of the Internet, (Pew 2010) ${ }^{[4]}$ had said, "in accordance with Sturgeon's Law, 90\% of everything is crud; therefore, $90 \%$ of internet writing is crud too." Harold Bloom as cited in Adler $(2008)^{[5]}$ sees the twentieth century as a 'chaotic age'. Those reflect what the current and future scenario of internet is.

The issues of contents overload are the real consequences of web 2.0 revolutions, less culture, less reliable news, and chaos of useless information as said by Keen $(2007)^{[6]}$ in his book the Cult of the Amateur. Gene Spaffordi as cited in the Future of the Internet (Pew 2010) ${ }^{[4]}$ reports the current network is full of inaccurate, misleading, and biased information that often crowds out the valid information. To validate those statements a poll was conducted on a blog http://www.ccomme.wordpress.com asking questions; 'free and freedom promotes on internet could make user unconsciously slip into crud contents'. The poll result shows $90 \%$ of the respondents agree on that question. Another result to a question; 'liberalization promote on the Internet influence the declining in moral and social value among youths' shows $90.91 \%$ agrees on that matters. There is chaotic order and disorder of unregulated content, content-overload and unstructured presentation in UGC environment on the Internet. The UGC has certainly made a significant contribution to the flooding of Internet content, largely attributable to its global and highly unstructured and uncontrolled nature. 
Canton (2007) ${ }^{[7]}$ writes in his book the Extreme Future that top trends will reshape the world, and artists are amongst top job by 2020 reveals more 'promises' on content overload in the future. With that 'promises' we can expect more visual pollution in the future. However, this visual pollution could turns up to be a visual opportunities. The responsibility to uncover the positivism from the Internet and UGC is the only way to success. Howard Rheingold in the Future of Social Relations (Pew 2010) ${ }^{[8]}$ has this "For many, life will be alienated, rushed, and confusing because of their involvement online. Others will choose or will learn or be trained to cope with dangers of an always-on lifestyle." And Luis Santos speaks in the Future of the Internet 3 (Pew, 2008) ${ }^{[9]}$, "The Web must still be a messy, fabulous, exciting, dangerous, poetic, depressing, elating place ...akin to life; which is not a bad thing". Despite the threat the Internet had there are many opportunities. It seems that the existence of the overwhelming visual is one of the opportunities.

Visual in 'golden age' is the prognostication of the future, said Clay Shirky, in the Future of the Internet (Pew 2010) ${ }^{[4]}$. A shift from written media to visual media will naturally allow visual to dominate cyberspace. Consistent to this phenomenon, user is less reading but more seeing, and Jakob Nielsen's ${ }^{[10]}$ alert on the situation, 'On the average Web page, users have time to read at most $28 \%$ of the words during an average visit; $20 \%$ is more likely.' Besides, because of the economic factors, many governments all around the world would not likely control the contents, except for few countries such as China for a certain reason. Malaysian would like to have access to the Internet without government interference and control. This is shown in an online discussion forums (Carigold, Mesra.net and Ustazah Bahyiah FB) outcome, most of the respondents wanted to have the capacity of 'reflective self-evaluation', only fewer agree that the government should have had the control over the Internet. That is to say that the visual contents would be more likely to continue evolving.

The visual and aesthetic of the content is consistent with many similarities. Visual properties bear the potential to be aesthetically experienced or at least affect aesthetic preferences (Leder, Belke, Oeberst and Augustin, 2004) ${ }^{[11]}$. Aesthetic, although universal has slight differences across the world. People concur and converge about the seven basic attributes (shape, scale, orientation, position, tone, texture, and color) and the Denis Dutton seven universal signatures (expertise or virtuosity, non-utilitarian pleasure, style, criticism, imitation, special focus, and imagination) in human aesthetic. The basic attributes shares across many disciplines and people generally in many cultures and regions accept each of these signatures. However, people also differ and diverge about aesthetic. A common visual appearance is no longer a marker for a commonly agreed style (Leder et al., 2004) ${ }^{[11]}$. In addition, user is very anxious to use new technology in producing contents generates 'diverse' form and style on aesthetic. New aesthetic is the new hybrid, approached without reference to the aesthetics of the past, (Lee, (n.d)) ${ }^{[12]}$. A new interpretation of aesthetic should include the diverse effect of visual contents.

Since man exists, and from the Lascaux cave painting to the current visual contents at cyberspace, the evolution of aesthetic expression continues. Hence, it is a thought for message purposes or solely for aesthetic feeling; it does express meaning and value. Hallnas and Redstrom (2002) ${ }^{[13]}$ see aesthetic as the logic of expressional, defining an expressional as "a thing that is designed to be the bearer of a certain expression." Because beauty is somehow, in everybody minds consciously or unconsciously he/she would certainly express the meaning and value of aesthetic throughout his or her actions. Every action a person makes had a cognitive component to assign meaning and an affective component to assign value, Theuma $(2007)^{[14]}$. Despite the platform differences, visual aesthetic has cognitive and affective component embedded in it.

Levi-Strauss 'Bricolage' (Deuze, 2006) ${ }^{[15]}$, 'Beardsley aestheticize everything' Leddy $(2008)^{[16]}$, and 'Dewey esthetic hunger' Shusterman $(2003)^{[17]}$, those are examples could lead to the consequences of a 'minimum taste' when producing aesthetic expression. User simply 
picks any image representation even for formal discussion forum proved a 'minimum taste' they had. This was reveals during an online forum at Putera.com when respondents gave reasons such as "whatever", "whatever available", "whatever suitable", "simply choose", and "likes", on an issue; "why user do not use their own photo especially for formal discussion forum'. Would this 'minimum taste' of new hybrid bring new meaning and new value to aesthetic? This could be one of the areas of interest. Additionally, this could be the answer to the logic of Jenkins 'low barrier' of aesthetic expression. Jenkins describes the participatory culture as a culture where everybody participates and express, and one does not need high taste to produce or express aesthetic, states this as 'low barrier' of aesthetic expression.

The logic of 'low barrier' of aesthetic expression in UGC, shown by some situations imply in aesthetic is scientifically natural and technically a way of social living. Strong feeling or sense of beauty is human nature and in spite, it is a way of living. It is normal that everyone likes beauty in its own taste, and beauty evokes happiness. It is scientifically natural and technically social that supports the logic behind the 'low barrier' to aesthetic expression. Therefore, we can expect a more growing content that are expressive. This condition certainly induce overload.

\subsection{CREATOR ROLES- RESPONSIBILITIES OR OPPORTUNIST}

Aesthetic could impress and influence. Generally, everything designed has purpose, some has functional purposes as Petersen, Iversen and Ludvigsen (2004) ${ }^{[18]}$ said 'aesthetic of use rather than aesthetic of appearance', but others intent to impress and influence viewer/ user. Design to impress and influence has the tendency to manipulate emotion and thought, especially those that emphasize visual in design such as architecture, graphic design, product design, fashion design, interior design, and multimedia design.

The gestalt, 'the whole is greater than the sum of the parts' grasps viewer attention as a whole explain the true aesthetic impression theory and the important of aesthetic impression in design. Michael Mills's Instant Recognition, and Linggard, Fernandes, Dudek and Brown $(2006)^{[19]}$, Instant Reaction studies show the aesthetic power the visual had. Lingaard's study has also proved by Theuma $(2007)^{[14]}$. H. Obendorf $(2009)^{[20]}$ study shows even minimal design invokes an aesthetic impression, while Tractinsky, Cokhavi, and Kirschenbaum $(2004)^{[21]}$ study also proved that the aesthetic impression is forming quickly. Strengthening those finding is Norman's study on human information processing, where 'first impression happen at visceral level and is unconscious', and visceral level happens at the early stage.

Aesthetic is so powerful and Plato realized that it could influence and potentially to corrupt. His concerned was the aesthetic could influence rather than the ideas of the visual, and thus they might cloud the truth rather than clarifying it, they can also strongly influence behavior and character. Aesthetic is so powerful that could ignore other indications. Theuma (2007) ${ }^{[14]}$ in his study stated that a very positive first impression might mean that a person disregards negative aspects encountered later. The creator in cyberspace creating contents and plays with emotion and thought whether for personal purposes or public purposes. Researchers have done quite extensive study on aesthetic and it relation to emotion and cognitive. Although they might use different terms such as judgment and reflection, this is also referring to cognitive, and terms such as affective, feeling, and mood is referring to emotion. The border between them has been extended and somewhat blurred.

Here is some study on aesthetic that involve cognitive and emotion. Leder et al. $(2004)^{[11]}$ in his information-processing model of aesthetic experience shows the cognitive-processing output is aesthetic judgment and aesthetic emotion. An aesthetic experience is a cognitive processes accompanied by continuously upgrading affective states, which appraised vice versa, resulting in an [aesthetic] emotion. His model is based on an analysis and context of modern art. Hagtvedt, Hagtvedt and Patrick $(2008)^{[22]}$ include affective [emotion] and cognitive [judgment] of aesthetic and intellectual appeals in measuring art perception. 
Bechara and Damasio $(2005)^{[23]}$ in their study state that the process of deciding advantageously is not just logical but also emotional. Popp (2009) ${ }^{[24]}$ also cited their work.

At cyberspace, people who create content are those who are incline to be expressive (one of the characteristics in participatory culture where everybody participates and is expressive) and those expression has emotional value. Expression is an action, which not only consists of cognitive but also affective component, in which affective component assigned value. Sometime people could not think, or need not to think so deeply, sometime people should think more and make a careful decision. In a time when people could not think, they use their gut to decide. That is where emotion comes and plays a role. A study emphasis on emotion and decision-making by Lingaard and Dudek $(2003)^{[25]}$ shows that emotional responses precede cognitive and have a lasting effect. Norman $(2005)^{[26]}$, in the 'emotional design' extends the role of emotion in design. Pham, Cohen, Pracejus, and Hughes $(2001)^{[27]}$ connect emotion and feeling to valuation and decision-making. Linggard et al. 2006 $6^{[19]}$, decisionmaking did not rely entirely on cognitive process.

One of the most notable sources of impression is the visual appearance. Beauty and aesthetic is attractive to human and psychologists surmise that humans have a cognitive bias to attractive people and things. Aesthetic as one of the visual factor could sway and bias and it will hold for the next level of judgment. As cited in Tractinsky et al. (2004) ${ }^{[21]}$, immediate affective reactions (Duckworth, Bargh, Garcia and Chaiken, 2002) ${ }^{[28]}$ and Pham et al. $(2001)^{[27]}$, may color and potentially sway successive cognitive processes. Even only simple pattern recognition is possible at visceral level, but it can bias the other levels of processing (Norman 2005) $)^{[26]}$.

The halo effect occurs when a first impression affects the evaluation of other attribute of a product. According to Linggard et al. 2006 ${ }^{[19]}$, 'halo effect' - pre-cognitive 'affective reaction' is a physiological response to what they see on the screen - a gut reaction. Hartmann, Sutcliffe, and De Angeli (2008) ${ }^{[29]}$ 'halo effects' were demonstrated in their study, in which attribution of good quality (aesthetics is one of the qualities) on one attribute positively influenced judgment on another, even in the face of objective evidence to the contrary. In the human decision-making and judgment literature, the phenomenon is typically referred to as a cognitive 'confirmation bias' Mynatt, Doherty \& Tweeny (1977), and Nisbett and Ross (1980) as cited in Linggard et al. (2006) ${ }^{[19]}$ and it occurs when participants search exclusively for confirmatory evidence supporting their initial hypothesis while ignoring disconfirmatory evidence.

In getting user attentions, the opportunist creator manipulating visual contents more than serve the functions. The opportunist creator who knows the power of aesthetic could impress and influence user, takes the advantages to sway and bias user's emotion and thought for their own benefits.

\subsection{USER OPPORTUNITIES ARE GROWING HIGH}

The above texts strongly support the notion that the situation at the cyberspace, especially in this case, the visual, would never be backward. At this point, user should alert to the threats the visual imposed, and always on the alert for them, and ready to deal with it if it happens. There are stages that lead to the optimum opportunities on the situation. Understand aesthetic, judge and reflect would assure a good decision while consuming the Internet contents.

Understand visual aesthetic would be one of the many opportunities at the cyberspace. Exposure to visual provides the user with a challenging situation to understand and cognitively master the artwork [visual] successfully (Leder et al., 2004) ${ }^{[11]}$. Because of the cyberspace is full of contents and visual is increasingly occupying the space and manipulated image-based is a reality (Deuze, 2006) ${ }^{[15]}$, it is a matter of overwhelming importance for user 
to understand the visual aesthetic. Researchers show a string of needs for user to understand visual aesthetic. Hoffmann and Krauss $(2004)^{[30]}$, stressed on the importance to have a framework on visual aesthetics, knowledge of principles and guidelines and to be able to apply visual aesthetics (...) for intended purposes. Meirelles $(2005)^{[31]}$ referring to computational media, emphasis the need on a new mode of visual sensitivity and conceptualization as well as a new mode of perception and creation of visual forms. Wenzel (n.d. $)^{[32]}$ found that the elements of aesthetic education are relevant to what makes a person.

However, user understanding of aesthetic seems still far beyond what scholars hope. A preliminary study shows users did not understand aesthetic. They did not know the meaning behind the visual they consumed. In a related poll at Putera.com, $70 \%$ of respondents said 'image they choose on the discussion forum is only a decoration, and not related to them' Only 30\% said 'image should be carefully chosen.' On the other hand, a poll conducted on blog http://www.ccomme.wordpress.com, has $100 \%$ agreed on 'choice of visual preferences reflect how people like things; and has certain aesthetic perception on that thing. Those perceptions reflect ones moral value'.

Knowledge on visual aesthetic and its purposes will help user understand the expressive contents. Jenkins (2006) ${ }^{[33]}$, in his white paper 'Confronting the Challenges of Participatory Culture: Media Education for the $21^{\text {st }}$ Century' had a strong suggestion on expressive citizenship emphasis on New Media literacy. Expression is one of the participatory culture forms. Therefore, it is important for users to have the 'expressive literacy', as a vital knowledge in this participatory culture.

The ability to reflects and judge the visual contents is very much depends on the understanding of the visual aesthetic being judge. The reflection and judgment process involves stages as in Norman 3-level theory of human behavior; integrate affective and cognitive process in those levels of reaction, behavioral and reflection. At reflection level, people make judgment and it is conscious, Norman $(2005)^{[26]}$, also cited in Linggard et al. $(2006)^{[19]}$, Lynch $(2006)^{[34]}$, Theuma $(2007)^{[14]}$, and Tractinsky and Zmiri (n.d. $)^{[35]}$. Aesthetic evaluation and interpretation occurs at all levels, but at reaction level, first aesthetic impressions were formed immediately, precede cognitive process, Norman $\left(2002^{[36]}, 2005^{[26])}\right.$, also cited in Tractinsky \& Zmiri (n.d. $)^{[35]}$. According to Norman 'Emotional Design', cognition interprets the world, leading to increased understanding and knowledge. Affect, which includes emotion, is a system of judgment: good or bad, safe or dangerous. It makes value judgments, the better to survive. With cognition and affect, together both will form a powerful understanding and evaluation of the visual aesthetic. In another study by Norman, Ortony, and Revelle, as cited in Norman (2002) ${ }^{[36]}$, each system affects the other. Some emotion (affective states) was driven by cognition, and cognition is influenced by affect.

Aesthetic reflects ones personality. Aesthetic reflection is an extra skill and become more important and could help enhance personality while performing task in this content-overload scenario. One example of aesthetic reflection could be trace in Wenzel (n.d.) ${ }^{[32]}$ work of aesthetic contemplation. Wenzel (n.d. $)^{[32]}$ referred this study to Kant's aesthetics and Wittgenstein's notion of language games. When one have to decide regardless of enough information to ensure the right decision, one should develop the ability to reflect and choose in such situations of under-determinacy. Practicing this ability makes self-consciousness and awareness of ones personal identity and continuity potentially more effective Wenzel (n.d. $)^{[32]}$. He also referred to Kant's "Our ability to be self-conscious and to be aware of our own identity is practiced and refined through aesthetic contemplation when we enjoy and 'feel' ourselves" (Kant, par. 1, 204).

Tractinsky, Katz, and Ikar $(2000)^{[37]}$ research finding support other social psychology findings that people associate a person's physical attractiveness with other personal attributes. Thus, in what is known as the "beautiful is good" stereotype, a person's attractiveness was found to affect how people perceive other attributes of that person (Dion et al. 1972) also cited in Tractinsky (2004) $)^{[21]}$. Kant as cited in Wenzel (n.d.) $)^{[31]}$, 'physical beauty is the sign of an 
interior beauty, a spiritual and moral beauty'. Similarly, at cyberspace, the outlook on the screen is the beauty, which further reflects its contents.

Counterbalance and self-control plays a significant role in the individual own fate and opportunities especially in the current situation where everything is available. According to Soshana Zuboff (1989) ${ }^{[38]}$ in her widely discussed and influential book In the Age of the Smart Machine: The future of work and Power, "(...) individual control over their own fates, and opportunities for self-fulfillment all take new shapes. The new information technology offers a historical opportunity to more fully develop the economic and human potential of our work organization." Lee Rainie in the Future of the Internet 2010 Survey Results, Pew Internet Research $^{[3]}$, concludes that "the openness has its own virtues and those who resist it will fall behind those who enable it. Those who took the opposite view were not necessarily happy about it, but they argued there are many forces pushing towards more control of the internet: (...) users themselves to ward off bad experiences. Some things will have to be managed, especially if the capacity of the current internet becomes strained." This conclusion by Rainie is parallel with the discussion forums output (Carigold, Mesra.net, and Ustazah Bahyiah FB) mention earlier that the individual should be self-control when dealing with internet contents. Canton (2007) ${ }^{[7]}$ opinion on lost of wisdom, ' (...) crowds is more likely to produce ignorance than wisdom', but his opinion then is criticized by Tapscott.

Stanford law professor Lawrence Lessig as quoted in Norman's book concludes, "We need to understand the limits in accuracy, taste, judgment, and understanding shot through all of our systems of knowledge," and Tapscott added that the democratized and fluid content creation mechanisms embodied in Web 2.0 are most readily able to tackle (Tapscott \& William, $2008)^{[1]}$. What is important is the ability to think, reflect, and balance the positive and negative meaning especially in this case, the aesthetic. Two aspects of persons, which are predominant in contemporary philosophy, one being epistemological, and the other moral (Wenzel (n.d, $)^{[32]}$ ), support this balance of positive and negative aesthetic. Both aspects are used to express someone's uniqueness and individuality (Wenzel (n.d, $)^{[32]}$ ), which is not the focus of this research. It is the people whom made the exponential growth of UGC, and it is the people whom to decide which one is right to consume, and be smart in decision-making and have good reasoning, if not wanting to drown in the 'crud content'.

User who understands aesthetic meaning behind the visual, could perform aesthetic reflections has the optimum opportunities and advantages of being competence, confidence and certainly, a personality enhanced experience in carrying task when participating in this chaotic but promising cyber world. Evident support will be part of judgment. User emotions and cognitive will always juggle because aesthetic will sway and bias the decision. User should aware 'halo effect' could mean another. User has to be able to reflect and make decision. At cyberspace, aesthetic reflection mean user is able to balance emotions and thought. It shows user personality.

\section{CONCLUSION}

This article supported by related literature, public-opinion polls and discussion forums explains the complete component of cyberspace; the space, the content, the creator, and the user, which are interconneted to one another with their own distinctive functions that allows it healthy growing and overwhelmingly overloaded. This article revealed that the UGC participatory will retains the good momentum because it serve every essential aspect of technical, psychology, social and economic respectively. Content-overload is inevitable and visual aesthetic will be more significant. This article also discovered that there is a logic behind the low barrier of aesthetic expression; it is scientifically nature and technically social. It fits human nature and is a way of living. Therefore, in the future, the 'low aesthetic' contents will appear more, and this induce new interpretation of aesthetic, which needs appreciation of new meaning and new value. 
The creator has a choice to be responsible of what been creating or to be an opportunist. The user opportunity is to understand visual aesthetic and acquire the knowledge of 'expressive' content would be essential in this participatory world. Alert and deal with the visual threats, understand aesthetic meaning and value, judge the affective, reflects cognitively, and decide firmly, besides, has the ability to counter-balance and engage self-control would make user competence, confidence and certainly enhances personality in carrying task when participating in this chaotic but promising cyber world.

Finally, the existence of the space, the existence of the content, the roles of the creator, and the user opportunities that make cyberspace growing. This compliments is a space of opportunities. The ideal mantra - 'not what you want', but 'how you want it to benefits you', would be true.

\section{FURTHER WORK}

Following this preliminary study, a visual analysis on participants 'avatar' image expression, looking for patterns, characteristics, meaning, and value from the communication and semiotic viewpoint is underway. The analysis output could provide not only a better understanding on Net gen knowledge on visual aesthetic and its relations to UGC, but may also serve to generate hypotheses about these relationships that can be empirically tested.

\section{REFERENCES}

[1] Tapscott, D. \& William, (2008). Wikinomics: How mass collaboration changes everything. USA: Penguin Group.

[2] Tapscott, D. (2009). Growing up digital. New York: McGraw Hill

[3] Anderson, J., \& Rainie, L. (2010). The future of internet 2010 survey results. Pew Internet, Pew Research Center.

[4] Anderson, J., \& Rainie, L. (February 19, 2010). The future of the Internet. Pew Internet \& American Life Project. Pew Internet, Pew Research Center.

[5] Adler, W. (2008). Cultural Clues. World Policy Institute. J 25 no3. Fall 2008.

[6] Keen, A. (2007). The cult of the amateur: How today's internet is killing our culture.

London: Nicholas Brealey Publishing.

[7] Canton, J., (2007). The extreme future. The top trends that will reshape the world in the next 20 years. USA: Plume Penguin.

[8] Anderson, J., \& Rainie, L. (July 2, 2010). The future of social relations. Pew Internet \& American Life Project. Pew Internet, Pew Research Center.

[9] Anderson, J., \& Rainie, L. (December 14, 2008). The future of the Internet III. Pew Internet \& American Life Project. Pew Internet, Pew Research Center.

[10] Nielsen, Jackob. (2008). How little do users read? Jakob Nielsen's Alertbox.

[11] Leder, H., Belke, B., Oeberst, A. \& Augustin, D. (2004). A model of aesthetics appreciation and aesthetic judgments. British Journal of Psychology, 95, 489-508.

[12] Lee, A. ( ) Aesthetic perception and technology. Design History and Theory. Art Centre College design.

[13] Hallnäs, L., and Redström, J. (2002). From use to presence: On the expressions and aesthetics of everyday computational things. In ACM Transactions on Computer-Human Interaction, Vol 9, No. 2, June 2002, pp. 106-124.

[14] Theuma, Matthew. (2007). Evaluating the aesthetics of Websites using materials analysis and visual design heuristics. MA Diss., UCL London.

[15] Deuze, Mark (2006). Participation, remediation, bricolage: considering principal component of a digital culture. The Information Society, 22: 63-75.

[16] Leddy. T.,(2008). The Aesthetics of junkyards and roadside clutter. http://www.contempaesthetics.org/newvolume/pages/article.php?articleID=207

[17] Shusterman, Richard. (2003). Pragmatism between aesthetic experience and aesthetic education. Studies in Philospphy and Education. 22: 403-412, 2003. 
[18] Petersen, M. G., Iversen, O. S., Krogh, P. G., and Ludvigsen, M. (2004). Aesthetic interaction: a pragmatist's aesthetics of interactive systems. In Proceedings 2004 Conference on Designing Interactive Systems: processes, practices, methods, and techniques (Cambridge MA).

[19] Lindgaard, G., Fernandes,G., Dudek, C. and Brown, J. (2006). Attention web designers: you have 50 milliseconds to make a good first impression. Behaviour \& Information Technology, 25, 2 (Mar. 2004), 115-126.

[20] H. Obendorf, (2009). Minimal aesthetics. Human-Computer Interaction Series, DOI 10.1007/978-1-84882-371-6_9

[21] Tractinsky, N., Cokhavi, A., and Kirschenbaum, M. (2004). Using ratings and response latencies to evaluate the consistency of immediate aesthetic perceptions of web pages. Proceeding of the Third Annual Workshop on HCI in MIS, Washinton, D.C., December 10$11,2004$.

[21] Hagtvedt, H., Hagtedt, R. \& Patric, V. M. (2008). The perception and evaluation of visual art. Empirical Studies of the Arts, Vol. 26(2) 197-218

[23] Bechara, A. and Damasio, A. R. (2005). 'The somatic maker hypothesis: A neural theory of economic decision', in Games and Economic Behavior, 52 (2): 336-372.

[24] Popp, Alexandru W. A. (2009). An understanding of infuence on human behavior. Munich Personal RePEc Archive. Available at http://mpra.ub.uni-muenchen.de/17367/ MPRA Paper No. 17367, posted 17. September $2009 / 22: 37$

[25] Linggard and Dudek (2003). Lindgaard, G. and Dudek, C., 2003. What is this evasive beast we call user satisfaction? Interacting with Computers, (15): 429-452.

[26] Norman, D. A. (2005). Emotional Design: why we love (or hate) everyday things. Basic Books: New York.

[27] Pham, M.T., Cohen, J.B., Pracejus, J.W., Hughes, G.D. (2001). Affect monitoring and the primacy of feelings in judgment. Journal of consumer research, 28 (2001), 167-188.

[28] Duckworth, K.L., Bargh, J.A., Garcia, M., and Chaiken, S. (2002). The automatic evaluation of novel stimuli. Psychological Science, 13, 6 (2002), 513-519.

[29] Hartmann, J., Sutcliffe, A. G., \& Angeli, A. D. (2008). Towards a theory of user judgment of aesthetics and user interface quality. ACM Transaction on Computer-Human Interaction, Vol. 15, No 4, Article 15, Publication date: Nov 2008.

[30] Hoffmann, Raff. \& Krauss, Kirstin. (2004). A Critical evaluation of literature on visual aesthetics for the web. Proceeding of SAICSIT, 2004, (pg 205-209).

[31] Meirelles, Isabel. (2005). Dynamic visual formation. Visible Language, no. 39.2, 100119.

[32] Wenzel, Christian Helmut (). Aesthetic aspects on persons in kant, schiller, and wittgenstein.

[33] Jenkins, H., Clinton, K., Purushotma, R., Robinson, A. J., \& Weigel, M. (2006). Confronting the challenges of participatory culture: Media education for the 21st century. MacArthur Foundation. Available at http://www.digitallearning.macfound.org/

[34] Lynch, Patrick.(2009). Visual decision making. Available at http://m.alistapart.com/about/

[35] Tractinsky, N. and Zmiri, D. (). Exploring attributes of skins as potential antecedents of emotion in HCI. In P. Fishwick (ed.), Aesthetic Computing. MIT Press (in press).

[36] Norman, D. A. (2002) Emotion and design. Attractive things work better. In interactions... july + august, ACM Press, pp. 36-42.

[37] Tractinsky, N., Shoval-Katz, A. Ikar, D., (2000). What is beautiful is usable. Interacting with Computers, 13, 127-145.

[38] Soshana Zuboff (1989). in the age of the smart machine: The future of work and power. USA: Basic Books Inc. 